\title{
RESENHA
}

\section{Aporias do punitivismo, especialmente no Ceará}

\section{Aporias of punitivism, especially in Ceará}

\section{Marcílio Dantas Brandão'}

1.Doutor em Sociologia (ufpe, 2017), Doutor em Ciências Sociais (EHess, 2017), pós-doutorado junto à Universidade Estadual do Ceará (uece), com bolsa Capes (2018-2019) e Funcap (2018-2020). Professor colaborador do Programa de Pós-Graduação em Sociologia da Uece. Orcid: 0000-0003-2978-4278 marcilio.brandao@uece.br

AZEVEDO, Estenio Ericson Botelho de; MOTA BRASIL, Glaucíria. (orgs.). Estado de exceção e políticas punitivas na sociedade contemporânea. Campinas: Pontes Editora; Fortaleza: EdUECE, 2018. Coleção Sociedade e Políticas Públicas, 2.

Reunindo um grupo bastante diversificado de estudiosos provenientes da Filosofia, do Serviço Social, da Sociologia, da Educação e do Direito, o livro organizado por Azevedo e Brasil (2018) é uma importante compilação de reflexões que competem para compreender a ascensão em nosso país do que Wacquant (2003) denominou de “onda punitiva”. O conjunto do trabalho é formado por quatorze capítulos originais, divididos em duas partes, sendo uma voltada à reflexão ortodoxamente reconhecida como teórica e outra que majoritariamente versa sobre problemas empiricamente observados no Ceará.

Em sua primeira parte, destacam-se reflexões a partir da obra de Michel Foucault e Giorgio Agamben, tomados como principais referências para analisar a democracia e suas exceções decorrentes do direito ao estado de sítio, 
do neoliberalismo, da biopolítica e da governamentalização da vida. $\mathrm{O}$ estudo destes conceitos e de suas relações com medidas emergenciais de segurança e estratégias sistêmicas de punição é a base dos primeiros capítulos que analisam diversos dispositivos de controle, disciplinamento e punição que caracterizam o Estado contemporâneo como Estado Penal, onde - segundo Peixoto (2018, p. 74) - o estado de exceção "não pode ser compreendido apenas no âmbito do direito. Na verdade, ele se apresenta em uma perspectiva paradoxal, como uma 'forma legal daquilo que não poderia ter forma legal' (AgAmben, 2004, p. 12)".

Como um "ponto fora da curva" desta primeira parte do livro, o texto do professor Odílio Alves Aguiar se apoia em discussões de Hannah Arendt sobre refugiados (que, diga-se de passagem, o autor muito apropriadamente destaca que foi mal traduzido em português para "fora da lei" ou "criminoso", a partir da noção de outlaw na versão original dos "Escritos Judaicos", de Arendt). Este capítulo é o último da primeira parte do livro e o referi como "ponto fora da curva" por duas razões principais: ${ }^{\circ}$ ) apoia-se na obra de Hannah Arendt, pensadora que não é mencionada nos capítulos precedentes e $2^{\circ}$ ) discorre sobre uma experiência factualmente encerrada nos campos de concentração, mas que - apesar de não ter nome frequente na contemporaneidade brasileira - é talvez uma das formas mais necessárias do estudo que nos permita compreender como atualmente a "incapacidade de tolerar qualquer oposição política" leva nossas minorias à condição análoga à de "refugiado" em sua própria terra, de outlaw onde o direito lhe parece injusto ou, simplesmente, de cidadão incompleto onde o princípio básico da democracia arendtiana do "direito a ter direitos” já não lhe pertence. Neste sentido, a resistência à alteridade no Brasil contemporâneo teria muito a ganhar com a disseminação de uma reflexão arendtiana tal como propõe Aguiar (2018), discutindo, por exemplo, os riscos da limitação do direito atual ao formalismo jurídico.

Enquanto a primeira parte é território de autoria exclusiva de filósofos, a segunda parte da obra tem diversidade de áreas de formação de seus autores, reunindo outros filósofos, mas também pesquisadores titulados nas áreas de Educação, Serviço Social, Sociologia e Direito. Trata-se da seção em que alguns problemas estruturais da sociedade brasileira são analisados a partir de 
casos observados no Ceará. Nesta segunda parte, as postulações de Arendt parecem emergir a uma posição de importância equivalente às de Foucault e Agamben. E, mesmo que surjam outras matrizes de influência reflexiva, o núcleo das discussões fica em torno destes filósofos, de alguns historiadores (como Benjamin), da criminologia crítica (à moda de Alessandro Baratta e Nilo Batista) e de cientistas sociais, como Loïc Wacquant.

A exemplo do texto da filósofa Cristiane Marinho, esta segunda parte tem também alguns capítulos mais afeitos à discussão teórica, como os de David Montenegro, Estenio Azevedo e Silmara Santos. Todos eles são ricos em suportes para a reflexão dos conceitos em que se apoiam: o poder foucaultiano de deixar viver ou fazer morrer, no caso de Marinho; a indissociação da violência com o desenvolvimento do Estado de Direito, nos casos de Montenegro e Azevedo; e, por fim, uma crítica ao capital em crise e sua criminalização da pobreza, que é o objeto da discussão estabelecida por Santos. Porém, há outros três capítulos onde se destaca um brilho sociológico de análise de problemas empíricos contemporâneos: drogas, letalidade por causa violenta e o grande crescimento da população privada de liberdade no Brasil dos últimos anos.

Neste bloco mais empírico da obra, o capítulo assinado por Cynthia Studart aponta como o proibicionismo das transações com drogas tem contribuído para a marginalização social dos jovens e criminalização da pobreza. Diferente do que é postulado no início da obra (AzEVEdo, BRAsil, 2018, p. 17), entendo que este seja mais um estudo sobre proibicionismo que sobre consumo de drogas. Bem fundamentado em dados do sistema judicial e penitenciário nacional, na bibliografia clássica sobre o tema e na trajetória da autora que vem investigando a questão desde seu doutoramento em Serviço Social, o texto sustenta que há um "avanço das funções penais do Estado em substituição às suas funções sociais” (stUdART, 2018, p. 201) e, deste modo, as substâncias denominadas "drogas" aparecem apenas como uma expiação da seletividade política e econômica que continua a criminalizar e punir principalmente negros e pobres no Brasil contemporâneo.

O capítulo assinado pelas assistentes sociais e professoras universitárias Glaucíria Brasil e Lucileila Almeida analisa a disseminação de práticas 
violentas que as autoras postulam como sendo uma sorte de "banalização do mal" que representa um "retrocesso" no interior do processo civilizatório. As autoras se apoiam em dados do Fórum Brasileiro de Segurança Pública (FBSP) e do Instituto de Pesquisa Econômica Aplicada (Ipea) que permitem afirmar de modo contundente que - apesar dos crimes violentos letais intencionais terem diminuído em alguns estados, como o Ceará (BRAsil, ALMEIDA, 2018, p. 259) - a letalidade das polícias cresceu no período observado (BRASIL, ALMEIDA, 2018, p. 262), assim como cresceu a vitimização de policiais (BRASIL, ALMEIDA, 2018, p. 268). Tudo isso aponta para um grande paradoxo do trabalho policial em um estado nacionalmente conhecido pelos recentes problemas de segurança pública; trata-se do paradoxo que consiste em enfrentar violência com violência.

Por fim, enfocando um estudo sobre dados do censo penitenciário de 2016, desenvolve-se um capítulo de autoria de um Defensor Público do Estado do Ceará que se inicia destacando a duplicação do número de presos no Brasil entre 2005 e 2016. A continuidade do ensaio de José Valente Neto lapida a gravidade da situação: $40 \%$ das detenções sem julgamento, $50 \%$ dos detidos com idade entre 18 e 29 anos, 64\% negros. Para completar o quadro de calamidade em que se encontra o sistema prisional, o autor introduz o que justifica a última parte do título desta resenha: o caso do Ceará, em meio a um cenário drástico, onde

Conforme o levantamento, quatro em cada dez presos brasileiros não tinham sido julgados quando o estudo foi concluído em junho de 2016. Em nove estados, havia mais presos sem condenação do que efetivamente julgados e condenados. O pior caso era o do Ceará, em que dois em cada três presos eram provisórios. [...] A taxa está bem acima da média brasileira, que passou de 37,5\% em dezembro de 2015 para 40,2\% em junho de 2016. O quadro é tão caótico que o Supremo Tribunal Federal, em 2015, entendeu que vigora no sistema penitenciário brasileiro um "estado de coisas inconstitucional", ou seja, uma violação generalizada de direitos. (VALENTE NETO, 2018, p. 271) 
Em seguida, o autor apresenta marcos regulatórios brasileiros do devido processo legal que pode conduzir à privação de liberdade, bem como discute parâmetros internacionais e menciona casos de outros países para concluir que há uma distorção no Brasil, onde abundam medidas alternativas à privação de liberdade ao mesmo tempo em que se usa cada vez mais o instrumento da prisão cautelar. A situação leva o autor ao alerta segundo o qual "Deve-se romper com a crença de que somente se faz justiça com a condenação e nunca com a absolvição" (VALENTE NETo, 2018, p. 291).

Deste modo, este segundo volume da Coleção Sociedade e Políticas Públicas complementa o que lhe precedeu (BRAsil, ALMEIDA, FrEITAs, 2015) e constitui mais um alerta sobre o sistema caótico em que podemos metaforicamente afirmar que se culpa a janela pela existência da paisagem. Em que pese o fato da obra ter uma perspectiva mais ortodoxamente teórica, os capítulos que destaquei são uma boa mostra de que, nos termos da metáfora supracitada, as drogas e a criminalidade violenta são apenas uma janela para a paisagem de grandes e profundas desigualdades socioeconômicas que não se alteram com a guerra às drogas nem com a onda punitiva e o crescimento da violência por parte das forças policiais. Não por acaso a obra se produziu no Ceará em 2018: ela foi um prenúncio do que viria a eclodir neste Estado no ano seguinte, com rebeliões em presídios e explosão da criminalidade violenta na capital e no interior. Apesar da aparente pacificação do problema local e regional em 2020, a paisagem nacional continua fundamentalmente igual: as polícias seguem mais violentas com os mais pobres e o sistema judicial persiste em um modelo operacional em que justiça para quem não pode pagar assistência judiciária rima muito mais com punição que com absolvição. Assim, o livro em tela continua relevante e representa uma sorte de libelo teórico com alguns estudos empíricos da paisagem em questão, revelando-se, portanto, uma leitura necessária para quem se inquieta com o regime de exceção e as políticas punitivas que se multiplicam em um cenário onde o Direito mais parece uma forma jurídica que um direito a ter direitos. 


\section{Referências}

AGUIAR, Odilio Alves. Hannah Arendt, o outlaw e o direito a ter direitos. In: AZEVEDO, Estenio E. B. de; BRASIL, Glaucíria M. (orgs.). Estado de exceção e políticas punitivas na sociedade contemporânea. Campinas: Pontes Editora; Fortaleza: EdUECE, 2018. p. 139-155.

AZEVEDO, Estenio E. B. de; BRASIL, Glaucíria M. (orgs.). Estado de exceção e políticas punitivas na sociedade contemporânea. Campinas: Pontes Editora; Fortaleza: EdUECE, 2018. Coleção Sociedade e Políticas Públicas, 2.

BRASIL, Glauciria Mota; ALMEIDA, Lucileila de S. Cardoso. Violência letal e controle estatal: os desafios da realidade cearense. In: AZEVEDO, Estenio E. B. de; BRASIL, Glaucíria M. (orgs.). Estado de exceção e políticas punitivas na sociedade contemporânea. Campinas: Pontes Editora; Fortaleza: EdUECE, 2018. p. 247-270. BRASIL, Glauciria Mota; ALMEIDA, Rosemary de Oliveira; FREITAS, Geovani Jacó de (orgs.). Dilemas da "nova" formação policial: Experiências e práticas de policiamento. Campinas: Pontes Editores, 2015.

PEIXOTO, Erika Gomes. Stasis: sobre a politização da vida e a exceção soberana. In: AZEVEDO, Estenio E. B. de; BRASIL, Glaucíria M. (orgs.). Estado de exceção e políticas punitivas na sociedade contemporânea. Campinas: Pontes Editora; Fortaleza: EdUECE, 2018. p. 73-95.

STUDART, Cynthia. Políticas sobre drogas no Brasil: proibicionismo, marginalização juvenil e criminalização da pobreza. In: AZEVEDO, Estenio E. B. de; BRASIL, Glaucíria M. (orgs.). Estado de exceção e políticas punitivas na sociedade contemporânea. Campinas: Pontes Editora; Fortaleza: EdUECE, 2018. p. 181-204.

VALENTE NETO, José. O sistema carcerário brasileiro. In: AZEVEDO, Estenio E. B. de; BRASIL, Glaucíria M. (orgs.). Estado de exceção e políticas punitivas na sociedade contemporânea. Campinas: Pontes Editora; Fortaleza: EdUECE, 2018. p. 271-292. WACQUANT, Loïc. Punir os pobres: a nova gestão da miséria nos Estados Unidos [A onda punitiva]. 3 ed. Rio de Janeiro: Revan; Instituto Carioca de Criminologia, 2003.

Recebido: 01/04/2021

Aceito: 01/04/2021 